\title{
How long should patients be surveyed for gastric cancer risk after Helicobacter pylori eradication therapy? 10 years is no longer enough
}

\author{
Mitsushige Sugimoto $^{1,2}$ (1) $\cdot$ Masaki Murata $^{3,4} \cdot$ Takashi Kawai $^{1}$
}

Received: 26 December 2019/ Accepted: 22 January 2020/Published online: 5 February 2020

(C) Japanese Society of Gastroenterology 2020

Helicobacter pylori infection is a major risk factor for the development of gastric cancer, particularly in East Asian populations, including Japan. Gastric cancer is caused by a multifactorial and multistep process mainly related to longterm infection with $H$. pylori in the gastric mucosa. Nevertheless, eradication treatment for $H$. pylori infection has also been shown to reduce the risk of gastric cancer in patients with atrophic gastritis, and recent meta-analyses confirmed the same effect in patients after endoscopic and operative resection for gastric cancer [1-3]. The Maastricht V/Florence Consensus Report issued by the European Helicobacter Study Group in 2017 recommended the eradication of $H$. pylori as first-line treatment in patients with peptic ulcer disease, autoimmune thrombocytopenia, chronic urticaria, iron deficiency anemia, gastric mucosa associated-lymphoid tissue lymphoma, and functional dyspepsia as a means of preventing gastric cancer [4]. For the first time anywhere, the Japanese health insurance system initiated coverage of $H$. pylori eradication treatment in all patients with endoscopically confirmed $H$. pyloriassociated gastritis in 2012. Against annual gastric cancer death rates of around 50,000 extending back more than 40 years, this expansion of coverage led to a significant

Mitsushige Sugimoto

sugimo@tokyo-med.ac.jp

1 Department of Gastroenterological Endoscopy, Tokyo Medical University Hospital, Shinjuku, Tokyo, Japan

2 Division of Digestive Endoscopy, Shiga University of Medical Science Hospital, Otsu, Shiga, Japan

3 Department of Gastroenterology, National Hospital Organization Kyoto Medical Center, Kyoto, Japan

4 Department of Gastroenterology, Shiga University of Medical Science Hospital, Otsu, Shiga, Japan decrease in deaths, from 48,427 in 2013 to 45,509 in 2016 [5]. National gastric cancer screening programs with upper endoscopy may have contributed to this decrease by decreasing the risk of diagnosis at an advanced stage, and by $H$. pylori eradication therapy after endoscopic diagnosis of $H$. pylori infection [6]. To date, however, most studies investigating the incidence of gastric cancer after eradication therapy have done so over the relatively short period of about 10 years, and it has remained unclear whether the chemopreventive effect of eradication therapy extends beyond 10 years, in consideration of pathological differentiation and the severity of gastric mucosal atrophy.

In this issue of Journal of Gastroenterology [7], Take et al. report a single-center retrospective cohort study of 2737 patients who received endoscopic follow-up survey after H. pylori eradication therapy for as long as 21.4 years (mean 7.1 years). Gastric cancer developed in 68 patients $(0.35 \%$ per year). Incidence was associated with the severity of gastric mucosal atrophy at baseline, developing in $0.15 \%$ per year with mild atrophy (Kimura-Takemoto classification: C-1 and C-2), $0.29 \%$ per year with moderate atrophy (C-3 and $\mathrm{O}-1)$ and $0.67 \%$ per year in patients with severe atrophy (O-2 and O-3) [8]. In their follow-up survey over $>20$ years after eradication therapy, the authors surprisingly showed that the risk of developing diffuse-type gastric cancer was greater in the second decade of followup than in the first, and that the risk of diffuse-type gastric cancer increased in patients with mild-to-moderate gastric mucosal atrophy at baseline. This observation suggests that the efficacy of $H$. pylori eradication therapy differs by both the severity of gastric mucosal atrophy at baseline and duration after eradication therapy.

More than $90 \%$ of $H$. pylori isolated in Japan carry the cagA factor, which is associated with increased 
proliferation and pro-inflammatory gene expression, and the vacA s $1 \mathrm{~m} 1$ type, which is associated with enhanced production of toxin with higher vacuolating activity [9-12]. For this reason, Japanese infected with $H$. pylori are at a higher risk for gastric atrophy, intestinal metaplasia and gastric cancer than $H$. pylori-positive European and US populations. The data tell the story: the age-standardized incidence rate (ASR) per 100,000 persons in 2018 was 39.6 in both sexes (57.8 in men and 23.5 in women) in Korea, 27.5 (40.7 and 16.0) in Japan and 20.7 (29.5 and 12.3) in China. These stand versus a world rate in 2012 of 12.1 (17.4 and 7.5, respectively) (https://www.wcrf.org/die tandcancer/cancer-trends/stomach-cancer-statistics). Thus, evaluating the association of $H$. pylori infection with gastric cancer risk in Japanese is an important step in formulating strategies to reduce the risk of gastric cancer.

In general, gastric cancer risk differs between patients with atrophic gastritis and patients after resection for gastric cancer. Metachronous cancer incidence in $H$. pyloripositive patients after resection of gastric cancer is $>2000$ per 100,000 person-years, which is greater than that in patients with gastritis alone (100-500 per 100,000 personyears). Recent meta-analyses showed that eradication therapy for $H$. pylori infection had a significant protective effect against the development of gastric cancer (Yoon (OR 0.42 , 95\% CI 0.32-0.56) [2]; Xiao (RR 0.50, 95\% CI 0.41-0.61) [3]; and Sugano (OR 0.46, 95\% CI 0.39-0.55) [1]). Accordingly, $H$. pylori eradication therapy should be required in all patients with $H$. pylori infection to prevent the development of gastric cancer. As Take et al. show in this issue [7], endoscopic surveillance should be continued beyond 10 years after eradication therapy for $H$. pylori irrespective of the severity of gastric atrophy.

Funding This research received no external funding.

\section{Compliance with ethical standards}

Conflict of interest The authors declare no conflict of interest.

\section{References}

1. Sugano K. Effect of Helicobacter pylori eradication on the incidence of gastric cancer: a systematic review and meta-analysis. Gastric Cancer. 2019;22:435-45.

2. Yoon SB, Park JM, Lim CH, et al. Effect of Helicobacter pylori eradication on metachronous gastric cancer after endoscopic resection of gastric tumors: a meta-analysis. Helicobacter. 2014;19:243-8.

3. Xiao S, Li S, Zhou L, et al. Helicobacter pylori status and risks of metachronous recurrence after endoscopic resection of early gastric cancer: a systematic review and meta-analysis. J Gastroenterol. 2019;54:226-37.

4. Malfertheiner P, Megraud F, O'Morain CA, et al. Management of Helicobacter pylori infection-the Maastricht V/Florence Consensus Report. Gut. 2017;66:6-30.

5. Tsuda M, Asaka M, Kato M, et al. Effect on Helicobacter pylori eradication therapy against gastric cancer in Japan. Helicobacter. 2017. https://doi.org/10.1111/hel.12415.

6. Jun JK, Choi KS, Lee HY, et al. Effectiveness of the Korean National Cancer Screening Program in reducing gastric cancer mortality. Gastroenterology. 2017;152(1319-1328):e7.

7. Take S, Mizuno M, Ishiki K, et al. Risk of gastric cancer in the second decade of follow-up after Helicobacter pylori eradication. J Gastroenterol. 2019. https://doi.org/10.1007/s00535-01901639-w.

8. Kimura K, Takemoto T. An endoscopic recognition of the atrophic border and its significance in chronic gastritis. Endoscopy. 1969;1:87-97.

9. Yamaoka Y, Orito E, Mizokami M, et al. Helicobacter pylori in North and South America before Columbus. FEBS Lett. 2002;517:180-4.

10. Yamaoka Y, El-Zimaity HM, Gutierrez O, et al. Relationship between the cagA 3 repeat region of Helicobacter pylori, gastric histology, and susceptibility to low $\mathrm{pH}$. Gastroenterology. 1999;117:342-9.

11. Sugimoto M, Ohno T, Yamaoka Y. Expression of angiotensin II type 1 and type 2 receptor mRNAs in the gastric mucosa of Helicobacter pylori-infected Mongolian gerbils. J Gastroenterol. 2011;46:1177-86.

12. Sugimoto M, Ohno T, Graham DY, et al. Gastric mucosal interleukin-17 and -18 mRNA expression in Helicobacter pyloriinduced Mongolian gerbils. Cancer Sci. 2009;100:2152-9.

Publisher's Note Springer Nature remains neutral with regard to jurisdictional claims in published maps and institutional affiliations. 